\title{
Discussion on the Exemplary Role of Post-Doctoral Party Members in Scientific Research
}

\section{Take Jinan University Post-Doctoral Research Station of Integrated Traditional Chinese and Western Medicine as an Example}

\author{
Sha Feng* and Guirong Li \\ Faculty of Medical Science, Jinan University, Guangzhou, China 510632 \\ *Corresponding author. Email: 2439770562@qq.com

\begin{abstract}
Postdoctoral fellows, which have deep significance for the construction of the research team, are indispensable part of the young and middle-aged talent team in universities. Based on the working example of the post-doctoral research station of Integrated Traditional Chinese and Western Medicine in Jinan University, we introduced the general situation of the post-doctoral research station. To provide the reference in further developing young Party member's scientific research quality and ability, we carried out a investigation to make clear the current situation of their scientific research capacity, and analyzed related factors for high capacity among post-doctoral Party members.
\end{abstract}

Keywords: Postdoctoral fellows, Party members, Scientific research capacity.

\section{GENERAL INSTRUCTIONS}

\subsection{General Information for Post-doctoral Fellows}

As innovative young scholars, post-doctoral fellows play a very important role in the development of universities $[1,2]$. Several studies shed light on the importance of young talents in research teams [3-6]. Multiple lines of evidence suggest that postdoctoral fellows appear more frequently as first authors in papers within the academic journals.

The post-doctoral CCP (Chinese Communist Party) members are particularly noticeable the backbone of young researchers, which can improve the sustainable development for the discipline construction and support scientific innovation. These analyses raise the question of the reasons behind these post-doctoral Party members' participation in China.

\subsection{Current Situation of Jinan University Post-doctoral Research Station of Integrated Traditional Chinese and Western Medicine}

Developing post-doctoral career vigorously is an important way to strengthen discipline construction and scientific research, to cultivate high-level talents, and to promote the organic combination of production and research. Jinan University post-doctoral research station of Integrated Traditional Chinese and Western Medicine was established in 2007, which was the first postdoctoral research station of Integrated Traditional Chinese and Western Medicine in Guangdong. It provided solid foundation for the academic communication, which supported by the original school of medicine, school of pharmacy, Key Laboratory of pathophysiology of State Administration of traditional Chinese Medicine, and Guandong-HongKong-Macau Institute of CNS Regeneration. It consisted of six research directions, including integrated Traditional Chinese and Western medicine for the prevention and treatment of major diseases, basic research on syndromes, research on the basis of medicinal materials and action mechanism of Traditional Chinese medicine, integrated Traditional Chinese and western medicine for 
the prevention and treatment of senile diseases, modern research on drug and prescription syndromes, and brain function and diseases. At present, it has 74 post-doctoral fellows, which are all under 35 years old, including 32 Party members. Young party members are in a highquality team among post-doctoral team. How to cultivate and develop this team, how to explore its exemplary leading role in the discipline construction is worthy of discussion.

\section{ANALYSIS OF POST-DOCTORAL PARTY MEMBERS' ACADEMIC CAPACITY}

\subsection{Number of Projects Approved by NSFC}

The results obtained from the preliminary analysis of post-doctoral Party members' academic capacity can be compared in Table 1. About 56 percent of the Party members in the station have been funded by National Natural Science Foundation of China (NSFC) funds; Among them, 5 Party members received the national Fund in 2017, 4 Party members received the national Fund in 2018, and 9 Party members received the national Fund in 2019 . The single most striking observation to emerge from the data comparison was that post-doctoral Party members had significant advantages, and their research output occupied an important place in the mobile station. These findings are consistent with postdoctoral Party members having skills, commitments, and incentives that are especially valuable for scientific research in China.

Table 1. The number of projects approved by the NSFC from 2017 to 2019

\begin{tabular}{|c|c|c|c|}
\hline $\begin{array}{c}\text { Projects in the } \\
\text { station }\end{array}$ & 2017 & 2018 & 2019 \\
\hline $\begin{array}{c}\text { Total Number of } \\
\text { projects approved } \\
\text { by NSFC }\end{array}$ & 6 & 6 & 16 \\
\hline $\begin{array}{c}\text { Number of Party } \\
\text { members' projects } \\
\text { approved by NSFC }\end{array}$ & 5 & 4 & 9 \\
\hline
\end{tabular}

\subsection{Number of Papers in A1-1 Area}

In this paper, A1-1 area papers refer to the academic papers published in the journal sources of JCR-SCI partition table 1 , which are generally regarded as the landmark achievements of this discipline. In 2019, Postdoctoral fellows at the station published 10 papers in A1-1 area, of which 6 were published by Party members. In terms of scientific fields, postdoctoral Party members were especially prominent in the number of papers in A1-1 area. Taking Zhang Tianpeng, a member of the CCP, as an example, he won the support of the NSFC fund in 2019 and published three papers on A1-1 area in 2019. However, with a small sample size, caution must be applied, as the findings might not be applicable to other groups in China. From the typical case, it demonstrated that the post-doctoral Party members had their own advantages in scientific research ability at least. If the development needs of Party members were identified effectively, it will stimulate the outstanding talents to stand out, and provide sustainable support for further development.

\section{THE REASON THAT POST-DOCTORAL PARTY MEMBERS' HIGH CAPACITY IN SCIENTIFIC RESEARCH}

\subsection{Strengthen Party and Academic Construction}

Prior studies that have noted the importance of the postdoctoral fellows, but the Chinese Communist Party construction of the postdoctoral team was rarely mentioned. A comparison of the two results (ie, projects approved by the NSFC and papers published in A1-1 Area) will help us identify obviously the differential presence of postdoctoral fellows. Party construction is constantly developing and changing with the requirements of the development of the new situation. Research capacity building and academic promotions also featured as important incentives. There are a number of important changes which need to be made. We must innovate and learn, accept new things, understand new situations and study new problems. The university Party committee leads and drives the quality improvement of Party building and ideological and political work by carrying out the work of "double leaders" teachers' Party branch secretary's studio construction and recruiting party members in high-level knowledge groups. In the meantime, we should create a working atmosphere of "integration and promotion of Party building and academy" to ensure the sustainable development of post-doctoral Party members by constantly improving the system.

\subsection{Improve the Cohesion of the Party Branch}

The academic team is not a simple collection of scholars, not just of academic interest, but a formal group with the same development goal [7], which has strong cohesion and mutual cooperation. This can be accomplished in many ways, including attending team meetings, social events and team-building activities. What's more, the relationship between the Party organizations of the post-doctoral fellows in Jinan University is generally the grass-roots Party organization in the department of the cooperative supervisor. The common values strengthen the academic connection between post-doctoral fellow and his 
supervisor, which is not fully incomparable to other research teams. Indeed, group core values play the central role in enhancing team cohesion and effectiveness. The findings of this study have a number of important implications for future practice. Due to the same academic development goals, the close combination of party building work and scientific research is achieved, and the leadership and organizational strength of the Party organization is transformed into a powerful driving force for the promotion of scientific research, which lead the political and professional progress of outstanding post-doctoral fellows.

\subsection{Promote Multidisciplinary Cooperation}

Postdoctoral fellows in the research team are likely to play a vital role in such fast-moving and competitive scientific research. In order to complete the research effectively requires effective multidisciplinary collaboration, which can bring different perspectives to the analysis. The importance of teamwork and communication is an evident theme, there is a view that the postdoctoral fellows is a valuable team member but can be more involved in the multidisciplinary team. Recently, the innovative measures of branch cooperation and joint construction have encouraged, which can strengthen the interconnection and interaction of Party building, promote the exchanges among disciplines, and explore more cooperation opportunities of mutual integration. Postdoctoral fellows with different disciplinary backgrounds have different professional knowledge, among which the cross-cooperation can promote the progress of a certain research subject. Through Party building, we should focus on the team, and enhance the cohesion of grassroots Party organizations in scientific research, and play exemplary role of Party members. This was achieved using a multidisciplinary, participatory process that can be applied to future research efforts in China.

\section{DISCUSSION}

Academic institutions work to ensure that postdoctoral fellows are focused on sustainable capacity building by combining service, skills transfer, and education. The university carried out the innovation and reform of the post-doctoral system in depth, and expanded the enrollment scale of postdoctoral fellows [8]. In that way, the overall strength of post-doctoral group has been rapidly improved, which has been an important part of the high-level innovative young talent team. Postdoctoral fellows' high-level learning abilities and stronger professionalization in scientific research make their contributions important to research.

We found that the likelihood of contribution of postdoctoral CCP fellows is significantly higher in research, with more NSFC projects and higher competitive papers, suggesting that postdoctoral $\mathrm{CCP}$ fellows are especially predominate in scientific research efforts in Jinan University Post-doctoral Research Station of Integrated Traditional Chinese and Western Medicine.

The findings from this study make several contributions to the current literature. The exemplary role of Party members will affect every member of the post-doctoral group. They can attract more excellent members to join the Party and guide the whole team to develop towards higher academic goals, thus promoting discipline construction. By setting up a typical model and striving for excellence, the enthusiasm of postdoctoral and even young teachers will be vigorously activated. The teachers with good political quality will be cultivated and developed into Party members, who will be teaching and scientific research backbone. It will benefit to the construction of the Party without blind area, and further enhance the cohesion effectiveness of the grass-roots Party organizations in university, which will have positive significance on the sustainable development of discipline construction.

\section{CONCLUSION}

This study investigated the contribution of postdoctoral Party members in scientific research by analyzing the number of projects and papers compared to other postdoctoral fellows in Jinan University Postdoctoral Research Station of Integrated Traditional Chinese and Western Medicine. However, The present study also had certain limitations in terms of challenges to acquire the career prospects for postdoctoral fellows as researchers. Further work should be undertaken to explore how to gain postdoctoral fellows' long-term career prospects in China. The uncertainty of career path for postdoctoral fellows may lead to the reduced attractiveness of science as a career [9]. At the same time, this individual assessment research may not met the need of science development in the new era and building innovation team in universities and research institutions, dispersed research teams' cohesive force, weakened the research innovation ability [10].

\section{REFERENCES}

[1] Carnethon, M.R., L.C. Neubauer and P. Greenland, Competency-Based Postdoctoral Education. Circulation, 2019. 139(3): p. 310-312.

[2] Sweedler, J.V., Career Advice for Graduate Students and Postdoctoral Fellows. Anal Chem, 2016. 88(5): p. 2513-4.

[3] Levitt, D.G., Careers of an elite cohort of U.S. basic life science postdoctoral fellows and the 
influence of their mentor's citation record. BMC Med Educ, 2010. 10: p. 80.

[4] Bowers, D.A., et al., National survey of clinical neuropsychology postdoctoral fellows. Clin Neuropsychol, 2002. 16(3): p. 221-31.

[5] Henderson, R.I. and N. Syed, The Mock Academic Faculty Position Competition: A Pilot Professional and Career Development Opportunity for Postdoctoral Fellows. Acad Med, 2016. 91(12): p. 1661-1665.

[6] Bowers, D.A., et al., National survey of clinical neuropsychology postdoctoral fellows. Clin Neuropsychol, 2002. 16(3): p. 221-31.

[7] Bodin, D. and C.L. Grote, Commentary: the postdoctoral residency match in clinical neuropsychology. Clin Neuropsychol, 2016. 30(5): p. $641-50$.

[8] Ross, R.G., L. Greco-Sanders and M. Laudenslager, An Institutional Postdoctoral Research Training Program: Increasing Productivity of Postdoctoral Trainees. Acad Psychiatry, 2016. 40(2): p. 207-12.

[9] Igami, M., S. Nagaoka and J.P. Walsh, Contribution of postdoctoral fellows to fast-moving and competitive scientific research. The Journal of Technology Transfer, 2015. 40(4): p. 723-741.

[10] Pfeiffer, J.K., Is the debate and "pause" on experiments that alter pathogens with pandemic potential influencing future plans of graduate students and postdoctoral fellows? mBio, 2015. 6 (1). 